Damjan Šimek, Katja Košir

Slovenia

\title{
Motivation for Participation in Competition and Avoidance of Competition: the Role of the Accuracy of Comparative Self-Evaluations of Academic Performance
}

\begin{abstract}
To investigate the role of academic achievement in the reasons for participation in and/or avoidance of competition more clearly, the presented research was aimed at assessing the role of the discrepancy between objective evaluations and subjective self-evaluations of academic performance in secondary school students. The differences between under-raters, accurate raters, and over-raters in their reasons for participation in and/or avoidance of competition were investigated. The study comprised 534 secondary school students. The results do not clearly indicate possible benefits of the positive bias; we found that under-rating may have some advantages in the sense of mastery orientation and self-improvement motives (upward comparison) in competitive situations. Concerning other reasons for participation in competition, as well as reasons for avoiding it, students were found to rely more on teachers' objective measure of academic performance than on the (in)accurate aspect of social comparison information.
\end{abstract}

Keywords: competitiveness, comparative self-evaluations, academic achievement, social comparisons, secondary school students 


\section{Introduction}

The classroom is a social context where it is almost impossible not to be compared with others. Peers are constantly providing social comparison information about different attributes, e.g., social acceptance, physical appearance and academic performance. Because of the fact that students spend a lot of time at school, their classroom environment represents an important context for their comparative evaluations, i.e., self-evaluation of abilities or other attributes relative to others. Studies that investigated the role of individuals' comparative evaluations of their abilities indicate that they are related to their performance. Blanton, Buunk, Gibbons, and Kuyper (1999) report that students' comparative evaluations in seven courses predict their academic achievement in these courses three months later; students that perceived themselves as better compared to other students improved their academic achievement. It seems that the perceived competence in relation to other group members can create the dynamics of a self-fulfilling prophecy through self-efficacy and performance expectations (Kuyper, Dijkstra, Buunk, \& van der Werf, 2011). However, the researchers who examined the accuracy of students' comparative evaluations found that they are often inaccurate (Dupeyrat, Escribe, Huet, \& Régner, 2011). Mostly, these inaccurate assessments are marked by a positive bias where students overestimate their academic performance, but some students tend to underestimate their academic performance. With a sample of adolescents, Dupeyrat et al. (2011) investigated the relation between students' comparative evaluations of academic performance in maths, achievement goals, and mathematics performance. They classified students in three groups with regard to the relationship between their self-evaluations of competence and actual mathematical competence: under-raters, accurate raters, and over-raters. The group of over-raters was the only group that progressed in math achievement from the second to the third term. They were also higher on performance approach goals compared to under-raters (but not to accurate raters). Mastery goals were not related to the accuracy of self-assessment. Similarly, Gonida \& Leondari (2011) found realistic self-appraisals of self-efficacy to be most adaptive with regard to students' interest, persistence, achievement goal orientations, and social goals. In the group of students with biased self-report on performance, underestimation of one's performance has been consistently associated with motivational costs and no benefits. Overestimation, however, has been associated with more costs (higher performance-avoidance goals), but not necessarily fewer benefits (high interest) compared to realistic self-beliefs. Thus, the research findings clearly indicate the 
maladaptive functioning of a negative bias, and suggest some possible benefits of a positive bias.

Other studies (e.g., Klassen, 2007), however, suggest that students with learning difficulties are more prone to overestimating their level of academic performance. It seems possible that the adaptive function of positive illusions about self is still an open research question. Previous research findings suggest that it is not the level of a positive bias per se that determines whether it is associated with costs or benefits, but the specific motivation that is underlying the bias (Gramzow, Elliot, Asher, \& McGregor, 2003). Such underlying motives can be classified into two groups: self-improvement motives (upward comparison), and self-enhancement motives (downward comparison). Dijkstra, Kuyper, van der Werf, Buunk, and van der Zee (2008) report that students prefer to compare their performance to students who perform better than themselves (i.e. upward comparison). However, in that case, some similarities with their comparison targets are needed to allow them to view their peers as a meaningful source of comparison information.

\section{Motivation for the participation in competition}

In the 1990s, the field of competition was subjected to a significant change of paradigm as multidimensional approaches revealed positive aspects of competition in education (Deutsch, 1990; Fülöp, 1992; Ryckman, Hammer, Katzor, \& Gold, 1990; Ryckman, Hammer, Katzor, \& Gold 1996; Thornton, Ryckman, \& Gold, 2011). Franken and Brown (1995) defined five motives for participation in competitive situations: (1) the need to win, (2) improving performance, (3) the motivation to put forth effort, (4) the preference for difficult tasks and (5) the wish to perform well. Šimek (2008) analyzed the relationship between competitive orientations and grade point average (GPA) in 747 secondary school students. The highest need to win as well as the highest satisfaction that comes from improving performance on a task well done was characteristic of the secondary school students with the highest GPA. The students who were repeating the school year exhibited the lowest level of the need to win, and, at the same time, the lowest level of the improving performance on a task well done; their goal orientation was failure avoidance. Fülöp (1992) states that the competitive school environment suits the students with high academic achievement because they actively seek opportunities to develop their abilities in a competitive environment. Previous research showed that competitiveness itself does not destroy intellectual achievements and that in the circumstances of the performance-orientated school environment, the most 
capable students can maximize their academic performance by being simultaneously task- and performance-orientated (Pintrich, 2000).

\section{Motivation for competition avoidance}

Ryckman et al. (2011) described another form of neurotic competitiveness: competition avoidance. Participants who were higher in competition avoidance showed higher levels of self-handicapping, greater fears of both success and failure, and higher levels of neuroticism. In exploring the motivation for avoidance of competition, Franken and Prpich (1996) state two specific reasons. Self-image concerns refer to the individual's fear regarding the outcome of competition: fear of failing or looking bad. Performance concerns relate to the individual's fear associated with the process of performing a task: self-consciousness, nervousness, and the need to meet high expectations of others. Franken and Brown (1995) find that if the competitive situation triggers ego-orientation, an individual can dislike competition due to self-image concerns, and accordingly, if the competitive situation triggers taskorientation, the individual avoids competition because it may disturb the process of performing a task. Regarding the GPA, Šimek (2008) found that there are no significant differences in performance concerns and self-image concerns in students. However, the role of the discrepancy between the objective academic performance and the self-evaluation of academic achievement needs to be further explored.

\section{The presented study}

To view the role of academic achievement in the reasons for participation in and avoidance of competition more clearly, the purpose of the presented research was to assess the role of the discrepancy between objective evaluations and subjective self-evaluations of academic performance in secondary school students. We examined the differences in the reasons for participation in competition and avoidance of competition between under-raters, accurate raters, and over-raters, and controlled the influence of objective academic achievement.

\section{Method}

\section{Participants}

The participants in the study were 534 secondary-school students: 224 (41.9\%) male and $320(58.1 \%)$ female students. The participants were students of 21 dif- 
ferent classes of three Slovenian secondary schools. Their age range was 16 to 19 $(\mathrm{M}=17.18, \mathrm{SD}=.74)$.

\section{Measures}

Objective academic performance. We used the final grade in the previous school year as an operative objective and verifiable criterion of academic performance. In the Slovenian school system the final mark is a reflection of the most prevalent marks in different subjects, and is expressed in the whole number from 1 (insufficient) to 5 (excellent).

Discrepancy between objective and subjective measures of academic performance refers to the discrepancy between the final mark (below average: 1, 2; average: 3 , above average: 4,5 ), and the category of subjective evaluation of academic achievement in comparison to one's peers. The students were asked to compare their academic performance with other students in their class. Comparative evaluations of academic performance were assessed using one question: "Compared to the majority of my peers, I would say that my academic performance is..." The participants then evaluated their academic achievement according to three categories: 1-worse than my peers, 2 - the same as my peers, 3-better than my peers.

The students who underestimate their academic performance subjectively rate their performance lower than that measured by the final mark. The students who overestimate their academic performance subjectively rate their performance higher than that measured by the final mark. Accordance between subjective and objective measures of academic achievement refers to the same level of objective and subjective evaluations of academic performance.

To measure different reasons for participating in competitive situations, we used the 19-item Competitiveness/Mastery Questionnaire (CMQ; Franken \& Brown, 1995), which measures five dimensions: (1) the importance of winning (WIN), (2) improving one's performance (IP), (3) motivation to put forth greater effort (MPFE), (4) satisfaction that comes from performing well (PW), and (5) the preference for difficult tasks (DT). In the presented research, four factors were extracted using principal components analysis and the Kaiser criterion. The items of IP and those of PW were joined into the same factor, which was named Improving Performance on a Task Well Done (IPPW). Franken and Brown (1995), Franken and Prpich (1996) and Šimek (2008) report internal consistency of the subscales with alpha-coefficients ranging from .60 to .89 .

To measure the components of avoidance of competition, two instruments were used. The 8-item Self-Image Concerns Scale (SIC; Franken and Prpich, 1996) was used to measure self-image concerns due to expected potential negative outcomes 
in the competitive situation. Franken and Prpich (1996) reported high reliability of the scale (.84), and Šimek (2008) determined the same for the Slovenian version (.87). In order to measure perceived negative influences of the competitive situation on performance, i.e., on the process of task execution itself, the 4-item Performance Concerns Scale (PC; Franken and Prpich, 1996) was used. Similar to Franken and Prpich's (1996) reported reliability (.89), Šimek (2008) reported adequate reliability also for the Slovenian translation of the scale (.80).

In all the scales measuring competitiveness, a five-point rating scale ranging from never (1) to always (5) was used.

\section{Procedure}

With the consent of the school principals, the research was conducted during regular class hours with the teachers absent in April and May.

\section{Results}

Means and standard deviations across the students who are under-raters, accurate raters and over-raters of their academic performance, as well as ANOVAs, post-hoc tests, alpha reliability coefficients, and effect sizes are shown in Table 1. The students who underestimate their academic performance have the highest verifiable academic performance, and the students who overestimate it, the lowest. Post-hoc comparisons showed significant differences between all the three groups; the effect size is medium. Significant differences across groups occurred in three dimensions of competition. Post-hoc comparisons showed that the students who underestimate their academic performance have a higher score on improving performance on a task well done, compared to the students who overestimate their academic performance. The under-raters have the highest and the over-raters the lowest scores on both competition avoidance dimensions; post-hoc comparisons showed that the under-raters and the accurate raters exhibit more performance concerns than the over-raters, whereas the differences between all the three groups in self-image concerns are significant. For the relation between the students' discrepancy between objective and subjective measures of academic achievement and dimensions of competition, all the reported effect sizes are small. Alpha reliability coefficients are adequate for all the dimensions, except for the preference for difficult tasks (.60). 
Table 1. Descriptive statistics, alpha reliability coefficients, and univariate ANOVAs across students who underestimate, are accurate raters, or overestimate their academic performance

\begin{tabular}{|c|c|c|c|c|c|c|c|c|c|c|}
\hline & \multicolumn{2}{|c|}{$\begin{array}{l}\text { Under- } \\
\text { raters } \\
(\mathrm{n}=86)\end{array}$} & \multicolumn{2}{|c|}{$\begin{array}{c}\text { Accurate } \\
\text { raters } \\
(\mathrm{n}=353)\end{array}$} & \multicolumn{2}{|c|}{$\begin{array}{c}\text { Over- } \\
\text { raters } \\
(\mathrm{n}=95)\end{array}$} & \multirow[t]{2}{*}{$\mathrm{F}$} & \multirow[t]{2}{*}{ df1 } & \multirow[t]{2}{*}{ df2 } & \multirow[t]{2}{*}{$\eta 2$} \\
\hline & $M$ & $S D$ & $M$ & $S D$ & $M$ & $S D$ & & & & \\
\hline $\begin{array}{l}\text { Objective academic } \\
\text { performancea }\end{array}$ & 3.91 & 0.84 & 3.22 & 0.70 & 2.43 & 1.00 & $81.04^{\star * *}$ & 2 & 531 & 0.234 \\
\hline \multicolumn{11}{|c|}{ Reasons for participating in competition } \\
\hline $\operatorname{IPPWb}(\alpha=0.74)$ & 3.70 & 0.52 & 3.74 & 0.56 & 3.55 & 0.62 & $4.35^{\star *}$ & 2 & 531 & 0.016 \\
\hline WIN $(\alpha=0.77)$ & 2.66 & 0.84 & 2.56 & 0.80 & 2.70 & 0.84 & 1.36 & 2 & 531 & 0.005 \\
\hline $\operatorname{MPFE}(\alpha=0.74)$ & 3.01 & 0.95 & 3.06 & 0.93 & 3.24 & 0.96 & 1.76 & 2 & 531 & 0.007 \\
\hline $\mathrm{DT}(\alpha=0.60)$ & 2.91 & 0.70 & 2.95 & 0.76 & 2.94 & 0.80 & 0.64 & 2 & 531 & 0.002 \\
\hline \multicolumn{11}{|c|}{ Components of avoidance of competition } \\
\hline $\operatorname{PCc}(\alpha=0.83)$ & 2.97 & 0.94 & 2.72 & 0.98 & 2.43 & 0.90 & $7.10^{* * *}$ & 2 & 531 & 0.026 \\
\hline $\operatorname{SICd}(\alpha=0.89)$ & 2.92 & 0.94 & 2.66 & 0.84 & 2.41 & 0.78 & $8.36^{\star * \star}$ & 2 & 531 & 0.031 \\
\hline
\end{tabular}

Note. Bonferroni's post-hoc comparison showed the following significant differences: a under-raters $>$ accurate raters $>$ over-raters; $b$ under-raters $>$ over-raters; $c$ under-raters $>$ accurate raters $>$ over-raters; $\mathrm{d}$ under-raters $>$ accurate raters $>$ over-raters; ${ }^{*} p<.05,{ }^{* *} p<.01,{ }^{* * *} p<.001$.

\section{Academic achievement as a covariate of effects}

Since the measure of the students' discrepancy between objective and subjective measures of academic achievement is based on the students' objective academic performance, in the ANOVA the two influences - the influence of the real GPA and the influence of self-enhancement/self-protection cannot be separated. Thus, we cannot conclude whether the results are the consequence of the discrepancy or the consequence of the objective academic achievement. Therefore, we performed additional analyses in which academic achievement was controlled (ANCOVA).

The covariate academic achievement was significantly related to the dimension of improving performance on a task well done, $\mathrm{F}(1,532)=27.16 ; \mathrm{p}<.001 ; \eta^{2}=$ 0.049 . The effect of the students' discrepancy between objective and subjective measure of academic achievement remained significant for this dimension after controlling for the effect of academic achievement, $\mathrm{F}(2,531)=2.71 ; \mathrm{p}<.05 ; \eta^{2}=$ 0.010 . However, Bonferroni's post hoc comparison showed that only the difference between the under-raters and accurate raters was significant $(\mathrm{p}<.05)$.

For the dimensions of need to win, motivation to put forth greater effort, and preference for difficult tasks, the effect of the students' discrepancy between objec- 
tive and subjective measure of academic achievement remained insignificant after controlling for the effect of academic achievement; however, academic achievement was a significant covariate for the dimensions of need to win, $\mathrm{F}(1,532)=$ 7.34; $\mathrm{p}<.001 ; \eta^{2}=0.014$, and preference for difficult tasks, $\mathrm{F}(1,532)=11.47$; $\mathrm{p}<.001 ; \eta^{2}=0.021$.

For both avoidance of competition dimensions, the effect of the students' discrepancy between objective and subjective measure of academic achievement was no longer significant after controlling for the effect of academic achievement (performance concerns, F $(2,531)=1.40$; self-image concerns, F $(2,531)=2.42$ ). However, academic achievement was a significant covariate for the dimensions of performance concerns, $\mathrm{F}(1,532)=11.75 ; \mathrm{p}<.01 ; \eta^{2}=0.021$, and self-image concerns, $\mathrm{F}(1,532)=8.51 ; \mathrm{p}<.05 ; \eta^{2}=0.016$.

\section{Discussion}

What role does the accuracy of the academic self-evaluations play in the reasons for participation in competitive situations? For improving performance on a task well done, the effect of the students' discrepancy between objective and subjective measures of academic achievement remains significant even after controlling for the effect of academic achievement. However, only the difference between the under-raters and the accurate raters was significant, indicating that the students who underestimate their academic performance have a higher score on improving performance on a task well done, compared to the students who overestimate it. Pintrich (2000) stated that students who are most successful focus both on mastery and on performance. Improving performance on a task well done, as a motive for participation in a competition, indicates mastery orientation in the approach to competition, which, associated with performance orientation, may enable underraters to have the highest levels of academic achievement. Another explanation could be that students who underestimate their own academic performance are never satisfied with their achievement and, thus, have mastery orientation-the orientation that guides their behavior toward constant self-improvement. In other motives for participation in competition, differences between the groups of students according to the accuracy of the comparative self-evaluations were not found. However, since academic achievement was a significant covariate in two dimensions of competitiveness, we may confirm that in the students' reasons for participating in competition, the objective measures of academic performance seem to be more important than the subjective social comparison aspect. It seems 
that in most of the reasons for participation in competition, such as winning, getting motivation to put forth effort, or excelling in difficult tasks, the students rely more on teachers' measures than on the comparison to others.

For avoidance of competition dimensions, the effect of the students' discrepancy between objective and subjective measure of academic achievement was no longer significant after controlling for the effect of academic achievement. Because academic achievement was a significant covariate in both dimensions, we may confirm that in the students' reasons for avoiding competition, the objective measures of academic performance seem to be more important than the subjective aspect of (in)accuracy of interpersonal comparison information.

Contrary to some other findings (e.g., Gonida \& Leondari 2011), our research does not clearly indicate possible benefits of the positive bias. We found that under-rating may have some advantages in the sense of mastery orientation, i.e., self-improvement motives in competitive situations. The students who underestimate their academic performance have a higher score on improving performance on a task well done. In all other dimensions of competitiveness, the discrepancy between objective evaluations and subjective self-evaluations of academic performance is less important than the objective measures. It seems that in the reasons for avoidance of competition, as well as in most reasons for participation in it, the students rely more on teachers' objective measure of academic performance than on the (in)accurate aspect of social comparison information. However, the reverse is also possible: (objectively) high-performing students are more motivated to enter competitive situations because they expect to excel in them and to verify their high academic self-concept. They want to further self-enhance through new success and to confirm that they are really good. On the other hand, those who are less successful avoid competition because of the fear to experience failure again. That is the essence of self-enhancement: to seek positive self-evaluation and avoid negative self-evaluation.

\section{Limitations and future directions}

Because of the low reliability of the Preference for difficult tasks scale, analysis that includes this dimension should be interpreted with caution. Further exploration of the reliability of this scale is needed.

Gender has been reported as an important factor in the assessment of one's academic performance (Kuyper et al., 2011). Future studies should also examine how the accuracy of the comparative self-evaluations of academic performance, with regard to the motivation to participate/avoid competition, reflects gender differences. 


\section{References}

Blanton, H., Buunk, B.P., Gibbons, F.X., \& Kuyper, H. (1999). When better-thanothers compare upward. Journal of Personality and Social Psychology, 76, 420-430.

Deutsch, M. (1990). Forms of social organization: Psychological consequences. In: H.T. Himmelweit \& G. Gaskell (Eds.), Societal Psychology (pp. 157-176). Newbury Park, CA: Sage.

Dijkstra, P., Kuyper, H., van der Werf, G., Buunk, A., \& van der Zee, I.G. (2008). Social Comparison in the classroom: A review. Review of Educational Research, $78,828-879$.

Dupeyrat, C., Escribe, C., Huet, N., \& Régner, I. (2011). Positive biases in selfassessment of mathematics competence, achievement goals, and mathematics performance. International Journal of Educational Research, 50, 241-250.

Fülöp, M. (1992). Cognitive concepts on competition. International Journal of Psychology, 27, 316-322.

Franken, R.E., \& Brown, D.J. (1995). Why do people like competition? Personality and Individual Differences, 19, 175-184.

Franken, R.E., \& Prpich, W. (1996). Dislike of competition and the need to win. Journal of Social Behavior and Personality, 11, 695-712.

Gonida, E.N., \& Leondari, A. (2011). Patterns of motivation among adolescents with biased and accurate self-efficacy beliefs. International Journal of Educational Research, 50, 209-220.

Gramzow, R., H., Elliot, A., J., Asher, E., \& McGregor, H.A. (2003). Self-evaluation bias and academic performance. Journal of Research in Personality, 37, 41-61.

Klassen, R.M. (2007). Using predictions to learn about the self-efficacy of early adolescents with and without learning disabilities. Contemporary Educational Psychology, 32, 173-187.

Kuyper, H., Dijkstra, P., Buunk, A.P., \& van der Werf, M.P.C. (2011). Social comparisons in the classroom. Journal of School Psychology, 49, 25-53.

Pintrich, P.R. (2000). The role of goal orientation in self-regulated learning. In: V M. Boekaerts, P.R. Pintrich, M. Zeidner (Eds.), Handbook of Self-Regulation (pp. 452-502). New York, NY: Academic Press.

Ryckman, R.M., Hammer, M., Kaczor, L.M., \& Gold, J.A. (1990). Construction of a hypercompetitive attitude scale. Journal of Personality Assessment, 55, 630-639. 
Ryckman, R.M., Hammer, M., Kaczor, L.M. \& Gold, J.A. (1996). Construction of a personal development competitive attitude scale. Journal of Personality Assessment, 66, 374-386.

Ryckman, R.M., Thornton, B., Gold, J.A., \& Collier, S. (2011). Considering Competition avoidant individuals via the Big Five Model. Current Research in Psychology, 2, 108-114.

Šimek, D. (2008). The role of the motivation for education and competitiveness in self-handicapping strategies. Unpublished doctoral dissertation, University in Ljubljana, Faculty of Arts.

Šimek, D., \& Kobal Grum, D. (2011). Competitiveness and motivation for education in self-handicapping. Studia Psychologica, 53, 83-96.

Thornton, B., Ryckman, R.M. \& Gold, J.A. (2011). Competitive orientations and the Type A Behavior Pattern. Psychology, 5, 411-415. 